\title{
The generosity of the welfare state towards the elderly*
}

\author{
Mathieu Lefèbvre \\ CREPP - University of Liège \\ Boulevard du Rectorat 7 (B31) - B4000 Liège \\ Phone : ++32 43663103 \\ Fax : ++32 43663106 \\ Pierre Pestieau \\ CREPP - University of Liège, CORE, PSE and CEPR \\ Boulevard du Rectorat 7 (B31) - B4000 Liège \\ Phone : ++32 43663109 \\ Fax : ++3243663106
}

We acknowledge financial support from the belgian FNRS and from the European RTN research project. We are grateful to Michael Förster for his comments and remarks. We also thank two anonymous referees for their comments. Pierre Pestieau initiated this research while visiting DECVP at the World Bank. An earlier version of this paper was presented at the conference on "The Distributional Effects of Government Spending and Taxation", october 1516, 2004, The Levy Institute of Bard College. Comments from the participants were very helpful. 


\section{Abstract}

This paper distinguishes among three types of generosity of social security systems: average generosity, generosity towards early retirement and generosity towards the poor. On the basis of theoretical predictions, it examines the statistical correlations among those types of generosity for 14 OECD countries over the period 1985-2000. It also shows how they have evolved over time and tries to relate this evolution to the process of economic integration. There are three main findings, the first one being a positive relation between average social security spending and poverty alleviation. There is the negative relation between average spending and inequality reduction. Finally, over the period $1985-95$ one sees that poverty alleviation increases on average, but to a degree that decreases with economic openness.

Keywords: Social security, generosity, Bismarck, Beveridge.

JEL classifications: H55, I38, J26 


\section{Introduction}

Imagine a casual discussion involving three Eurocrats in a café on the Brussels Grand Place. They are attending a meeting on the "Future of Pensions in the EU". They are talking about the generosity of pensions. Each one contends that his own country is the most generous. The Belgian contends that his country is by far the most generous as it allows workers to retire as early as age 50 and that Belgium has the earliest effective age of retirement, i.e., 57 years for men. The Italian disagrees with this view: in his country the rate of replacement at age 65 is the highest, and that is the relevant measure of generosity. The third one, a Dutchman, completely disagrees with his two colleagues. "Generosity to whom?" he says: "In my country, pensions reduce the poverty rate among the elderly more than in any other country and that is what matters."

This imaginary discussion illustrates what this paper is all about. The concept of generosity is important, but at the same time very ambiguous. We distinguish among three types of generosity: one relying on average benefits, one focusing on early retirement, and finally one concerned with alleviating intragenerational inequality or poverty. A fourth definition would be one dealing with intergenerational redistribution, but it is outside of the scope of this paper.

Two questions are dealt with in the rest of this paper. First, what is the statistical correlation among our three concepts of generosity? Second, has this relation evolved over time, and to what extent is this evolution linked to economic openness? But before doing this', we provide some theoretical predictions as to the relationships among these three types of generosity. 


\section{Theoretical predictions}

\section{Political support of contributory systems}

In order to talk about the relation between average and redistributive generosity we have to introduce a traditional distinction between two extreme types of pension systems. The first one provides earnings-related benefits; it is also labeled Bismarckian, or contributive. At the other extreme, one finds pension systems whose benefit structure is such that the replacement rate (benefit to earning ratio) declines as earnings increase. These are also called redistributive, or Beveridgean with flat rate benefits. In reality pension systems are between these extremes, with Germany and France closer to the Bismarckian pole and the UK or the Netherlands closer to the Beveridgean pole.

Programs for the poor are poor programs: A number of recently developed political economy models argue that the size of a program depends on its degree of contributiveness. People vote for two parameters that reflect the two features of contributiveness and size. These votes are either sequentiali or simultaneous ${ }^{\mathrm{iii}}$. In either case and under plausible assumptions, there is a negative relation between size and contributiveness. This formalizes a well-known political economy proposition that targeting the benefits to the lower part of income distribution is unsustainable because of a lack of political support. This idea is popularized by the sentence: "Programs for the poor are poor programs". In other words, a broad program that caters to everyone, rich and poor, is most likely to get more political support than a program focusing just on the poor. 
Rich programs are good for the poor: We have just seen that contributory programs tend to be larger than redistributive ones. Do they improve the standards of living of the poor? In all likelihood. Within the Bismarckian tradition one finds the idea of a so-called minimum pension guarantee, i.e., a guarantee provided by the government that brings pensions to a minimum level, possibly by topping the existing entitlements, if there are any. If this guarantee is sufficient to lift a sizeable fraction of poor retirees out of poverty, then a contributory system can end up being very costly, having not much incidence on income redistribution while being efficient at alleviating poverty.

\section{Unavoidable distortions}

As shown by Gruber and Wise (1999) one of the main factors of early retirement is the implicit tax on prolonged activity, which in some countries is pretty high. Implicit taxation can be explained by the concern of governments with regard to the unemployment of young people. But even without such a concern, no government that tries to achieve some redistribution can avoid tax distortions. In a first best world it might be possible to redistribute income in a non distortionary way, in other words, in maintaining an equality between the marginal disutility of one more year of work and its marginal productivity. In the second best world non distortionary taxes are not available. Hence any redistribution entails taxes and pension benefits that induce workers to retire earlier than they would in a market economy, or in a first-best setting. ${ }^{\text {iv }}$ Such an observation would imply some positive correlation between early retirement generosity and redistributive generosity. 
However it can be shown that when the implicit taxes are really too distortionary, reducing them could have a double dividend: an improvement of income inequality among retirees and an increase in revenue. ${ }^{\vee}$ To conclude, the question of whether or not early retirement and either redistribution or poverty alleviation are positively correlated, can only be answered empirically.

\section{Race to the bottom}

One of the main alleged pitfalls of the ongoing economic integration is that it would impede redistributive policies at the national level, plus threaten the future of the welfare state. The basic idea is that mobile factors of production, labor or capital, can adjust their location to any international differentials in taxation or benefits. Hence national governments cannot abstract from such potential reactions when designing redistributive policies. To illustrate this point, assume a small open economy that provides retirees with a minimum pension benefit regardless of the value of their contributions. Assume also that workers can move freely across countries. It is likely that low-income workers will move in and that high-income workers will move out to other countries that have a contributory system. This would lead our small open economy to an unsustainable outcome, as it would be forced to adopt a less redistributive system. This is what is called "the race to the bottom", a notion that does not seem as radical as one could have feared a few decades ago. ${ }^{\mathrm{vi}}$ 


\section{Statistical relationship}

\section{The data}

We use two types of data for the average generosity of the pension system. AVGEN1 is simply the share of public pension spending in GDP, and AVGEN2 is the rate of replacement at 65 . This rate of replacement that comes from OECD is compiled for 6 typical households distinguished by earnings and marital status. Both are presented on Table 1 for the year 1995. Table 2 presents the Spearman correlation coefficients $^{\text {vii }}$ between these two indicators. The most and least generous countries according to AVGEN1, are Italy and Australia respectively. According to AVGEN2, the more generous is again Italy and the least is now Norway. These two concepts are not perfectly correlated, as AVGEN2 comes from the rate of replacement of only those retirees who are covered whereas AVGEN1 includes the rate of replacement, but also the rate of coverage that varies across countries.

For the generosity towards early retirement we also use two indicators: ERGEN1 is the effective age of retirement of male workers and ERGEN2 is the ratio of replacement at 55. As one can note, it is equal to 0 in some countries which don't have any such schemes. ERGEN1 ranges from 66.5 in Japan to 58.8 in the Netherlands and ERGEN2 ranges from 0.7 in Italy to 0 in the US, Norway, New Zealand, Japan, Canada and Australia. One observes some intersection between ERGEN1 and ERGEN2: countries characterized by generous rates of replacement for early retirees also count more early retirees than the others (implicit tax rates on prolonged activity are linked to these replacement rates). 
Finally we have two indicators of redistributive generosity. The first one concerns poverty alleviation (the difference between poverty without and with net public transfers). It is denoted POVGEN, and ranges from $78 \%$ in France to $25 \%$ in Japan. The second redistributive indicator consists of the ratio of the income share of public pensions in the first quintile to the same share in the top quintile. It is called INEGEN and ranges from 8.9 in Australia to 1 in France. One could expect these two indicators to be positively related. This is not the case as it appears on Table 2. Although surprising at first sight this is perfectly understandable. Poverty is just one aspect of inequality. A pension system can be distributively neutral on most of the income scale and at the same time provide the poor retirees with a good minimum pension. Also it can reduce inequality without alleviating poverty.

\section{TABLE 1 HERE}

\section{Correlations}

Table 2 presents the correlation coefficients for all these indicators. We have already discussed the correlations between indicators measuring the same type of generosity. We now turn to the relations for which we have some theoretical predictions.

Redistribution and average generosity: It appears that using both AVGEN1 and AVGEN2 and either correlation coefficient there is a negative relation between redistribution and average generosity. This seems to vindicate the political economy theory which says that the more contributory a pension scheme, the more generous it 
will be in average terms. Does that mean that average generosity is good for the poor? In fact, it appears that rich programs are in this instance good for the poor.

Poverty alleviation and average generosity: Indeed there is a positive though hardly significant relation between poverty alleviation and average generosity: this implies that schemes that are generous on average include programs that alleviate poverty.

Early retirement and redistribution: It is interesting to note a high correlation between ERGEN2 based on the replacement ratio offered to early retirees and either measure of average generosity. That indicates that there is no trade-off between early retirement and normal retirement. Instead, if we use the other indicator, ERGEN1, the coefficient is negative, but hardly significant. This implies that countries with generous but restricted early retirement, are also those that have a generous pension system on average.

Concerning the link between redistributive generosity and early retirement, we have a negative, but not significant correlation between INEGEN and ERGEN2, which does not vindicate the idea of a double dividend.

\section{TABLE 2 HERE}

\section{Changes over time}

The previous section was based on data concerning 14 countries and the year 1995. 
We also have data for 1985 and 2000 (see the appendix). This allows us to first check if the coefficients of correlation just discussed are changing over time. Then we look at the question of social dumping, given that the period 1985-2000 is one of increased economic integration.

\section{Stability of correlations}

On the basis of the previous section we are going to focus on three relations, the one between AVGEN1 and INEGEN, the one between AVGEN1 and POVGEN and the one between AVGEN2 and ERGEN2 to see how they evolve over time, namely over the period 1985-2000. This is presented on Table 3. It appears that there has been little change in these correlations among these types of generosity.

\section{TABLE 3 HERE}

\section{A race to the bottom?}

Table 4 gives the variations in the generosity indicators between the years 1985 and 1995 along with an indicator of economic openness ${ }^{\text {viii }}$ (TOI) that will be used to test the existence of a race-to-the-bottom.

Three evolutions are worth noting. First DPOVGEN, the variation in the extent of poverty alleviation due to social security is positive in 8 countries and negative in 6 . In other words one cannot see any trend towards less poverty alleviation. Second there is DINEGEN, which is negative in 10 out of 14 countries. Here we can say that there is 
a trend towards less reduction in inequality or alternatively towards more contributiveness. Finally there is DERGEN1, the change in the effective age of retirement. Very interestingly, DERGEN1 is negative everywhere. It thus seems that for reasons of globalization or ageing, all concerned countries are under pressure to reduce the generosity of their social security systems towards early retirement. Appendix Table A5 gives the changes in generosity for the period 1995-2000. We observe more or less the same pattern.

\section{TABLE 4 HERE}

If there is any race to the bottom, it is likely to be more intense in open economies. We use the level of TOI instead of the change because the indicator of openness is quite stable over the period considered. The level of trade openness is a structural feature of a country and should explain the existence of social dumping. Accordingly we try to see to what extent changes in POVGEN can be explained by the openness of the countries concerned. Appendix Tables A6-9 give the coefficients of correlation for the two periods, and for the whole sample of countries with and without Finland. Finland's figure for poverty alleviation is doubtful since part of the social security benefits are not taken into account. Indeed Figure 1 presents results that show that variation in poverty alleviation is negatively related to the degree of openness for the period $1985-1995^{i x}$. The $R^{2}$ is 0.62 . But it appears (see appendix A9) that this negative relationship no longer holds for the period 1995-2000.

FIGURE 1 HERE 


\section{Conclusion}

The main idea of this paper is that a social security system - including not only old age pension systems but also disability and unemployment insurance, early retirement scheme and welfare programs - can be labeled generous in a number of different ways. First it can be generous towards early retirement by offering workers aged 55-65 relatively high benefits. Second, it can be generous towards people who retire at the normal age (generally 65). Third it can be generous towards the poor retirees by giving them benefits well above their contributions.

To conclude, we have provided evidence for these three definitions of generosity, and shown that they are not closely correlated. The main result is that Bismarckian contributory programs tend to offer generous pensions that in turn benefit the poor. This is a vindication of the idea that programs for the poor are poor programs, and that rich programs are good for the poor. We also note the link between economic integration and redistribution. All in all variation in poverty alleviation is related to the openness of the economies concerned. 


\section{References}

Blöndal S. and S., Scarpetta, (1999) The retirement decision in OECD countries. OECD Economics department working paper 202.

Burniaux J.M., R. Duval and F., Jaumotte, (2004), Coping with ageing: a dynamic approach to quantify the impact of alternative policy options on future labour supply in OECD countries, OECD Economics department working paper, 371.

Casamatta, G., H. Cremer and P. Pestieau, (2002), The political economy of social security, Scandinavian Journal of Economics, 102, 503-522.

CATO, (2001), Economic Freedom of the World 2001, Fraser Institute.

Conde-Ruiz, J. and P. Profeta, (2003), What social security: Beveridgean or Bismarckian, unpublished.

Cremer, H. and P. Pestieau, (2003), The double dividend of postponing of the age of retirement, International Tax and Public Finance, 10, pp.419-434.

Cremer, H., J-M. Lozachmeur and P. Pestieau, (2004), Social security, retirement age and optimal taxation, Journal of Public Economics, 88, 2227-2258.

Förster, M., (2003), Income inequalities, poverty and effects of social transfer policies in traditional OECD countries and Central Eastern Europe. Patterns, trends and driving forces in the 1990s, PhD Thesis, University of Liège.

Gruber, J. and D. Wise, (1999), Social Security Programs and Retirement around the World, University of Chicago Press, Chicago.

OECD, (2003), Replacement rates, unpublished, OECD, Paris.

OECD, (2004), Social expenditures database, 1980-2001, OECD, Paris.

Pestieau, P. (2005), Globalization and redistribution, in B. Cantillon and J. Mark, eds, International Cooperation in Social Security. How to cope with Globalisation?, Intersentia, Oxford, 3-14, 2005.

Pestieau, P. (2006), Social security and the well-being of the elderly. Three concepts of generosity, European pension systems" Institute for European and International Studies, Luxembourg,2006 
Table 1 - Indicators of generosity, 1995

\begin{tabular}{lcccccc}
\hline & AVGEN1 & AVGEN2 & POVGEN & INEGEN & ERGEN1 & ERGEN2 \\
\cline { 2 - 6 } AUS & 3.798 & 0.376 & 57.000 & 8.9 & 61.8 & 0.000 \\
CAN & 5.400 & 0.571 & 46.854 & 3.4 & 62.3 & 0.000 \\
DNK & 9.718 & - & 65.270 & 3.6 & 62.7 & - \\
FIN & 9.739 & 0.594 & 30.831 & 3.9 & 59.0 & 0.528 \\
FRA & 12.106 & 0.783 & 77.979 & 1.0 & 59.2 & 0.499 \\
DEU & 11.174 & 0.525 & 70.100 & 1.4 & 60.5 & 0.370 \\
ITA & 13.324 & 0.800 & 55.675 & 1.4 & 60.6 & 0.700 \\
JAP & 5.915 & 0.637 & 25.400 & 3.6 & 66.5 & 0.000 \\
NLD & 8.002 & 0.589 & 59.700 & 3.1 & 58.8 & 0.687 \\
NZ & 5.580 & 0.439 & 70.200 & 3.2 & 62.0 & 0.000 \\
NOR & 7.507 & 0.321 & 58.200 & 2.2 & 63.8 & 0.000 \\
SWE & 10.627 & 0.735 & 73.205 & 1.2 & 63.3 & 0.250 \\
GBR & 8.740 & 0.457 & 53.387 & 3.5 & 62.7 & 0.232 \\
USA & 6.348 & 0.545 & 36.461 & 3.7 & 63.6 & 0.000 \\
\end{tabular}

Source: OECD (2004, 2003), Förster (2003), Blöndal and Scarpetta (1999). 
Table 2 - Correlation coefficients of generosity indicators 1995

\begin{tabular}{lcccccc}
\hline & AVGEN1 & AVGEN2 & POVGEN & INEGEN & ERGEN1 & ERGEN2 \\
\hline AVGEN1 & 1.000 & & & & & \\
AVGEN2 & $0.610^{* *}$ & 1.000 & & & & \\
POVGEN & 0.371 & 0.000 & 1.000 & & & \\
INEGEN & $-0.617^{* *}$ & -0.407 & $-0.694^{* *}$ & 1.000 & & \\
ERGEN1 & -0.370 & -0.258 & -0.268 & 0.173 & 1.000 & \\
ERGEN2 & $0.829^{* * *}$ & $0.633^{* *}$ & 0.236 & -0.451 & $-0.748^{* * *}$ & 1.000 \\
\hline *** & & & & & &
\end{tabular}

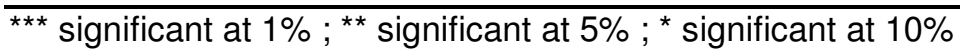


Table 3 - Evolution of coefficients of correlation

\begin{tabular}{lccc}
\hline & 1985 & 1995 & 2000 \\
\hline AVGEN1 and INEGEN & & & \\
& $-0.626^{* *}$ & $-0.617^{* *}$ & $-0.649^{* *}$ \\
AVGEN1 and POVGEN & & & \\
AVGEN2 and ERGEN2 & $0.582^{* *}$ & 0.371 & 0.349 \\
& & & \\
& $0.769^{* * *}$ & $0.633^{* *}$ & $0.584^{* *}$ \\
\hline
\end{tabular}


Table 4 - Change in indicators of generosity and trade openness 1985-1995

\begin{tabular}{lrrrrrrr}
\hline & DAVGEN1 & DAVGEN2 & DPOVGEN & DINEGEN & DERGEN1 & DERGEN2 & TOI \\
\cline { 2 - 5 } & -0.003 & 0.017 & 8.600 & -2.010 & -0.9 & 0.000 & 7,20 \\
CAN & 1.339 & -0.003 & -0.170 & -0.804 & -1.5 & 0.000 & 7,60 \\
DNK & 1.464 & - & 9.010 & -0.090 & -1.8 & - & 7,10 \\
FIN & 1.578 & 0.039 & -10.723 & -0.665 & -1.1 & 0.093 & 6,70 \\
FRA & 1.444 & -0.009 & 9.869 & -0.132 & -2.1 & -0.046 & 6,50 \\
DEU & 0.272 & -0.082 & -1.400 & -0.041 & -1.7 & -0.034 & 8,50 \\
ITA & 2.323 & 0.000 & 7.157 & -1.152 & -1.0 & 0.000 & 7,40 \\
JAP & 1.052 & - & 12.200 & -0.010 & -0.7 & - & 6,50 \\
NLD & -0.125 & -0.048 & -0.100 & 0.092 & -2.6 & -0.035 & 8,40 \\
NZ & -1.358 & -0.015 & 6.000 & 0.510 & -0.9 & 0.000 & 7,50 \\
NOR & 1.522 & -0.036 & 4.400 & -0.067 & -2.2 & 0.000 & 7,40 \\
SWE & 1.435 & -0.029 & -10.867 & 0.323 & -1.3 & -0.026 & 7,80 \\
GBR & 1.149 & 0.072 & -7.270 & 0.278 & -1.9 & -0.024 & 8,50 \\
USA & -0.133 & 0.028 & 2.467 & -0.247 & -0.6 & 0.000 & 7,80 \\
\hline
\end{tabular}

Source: TOI (CATO 2001) 
Figure

Figure 1 - Poverty and openness 1985-1995

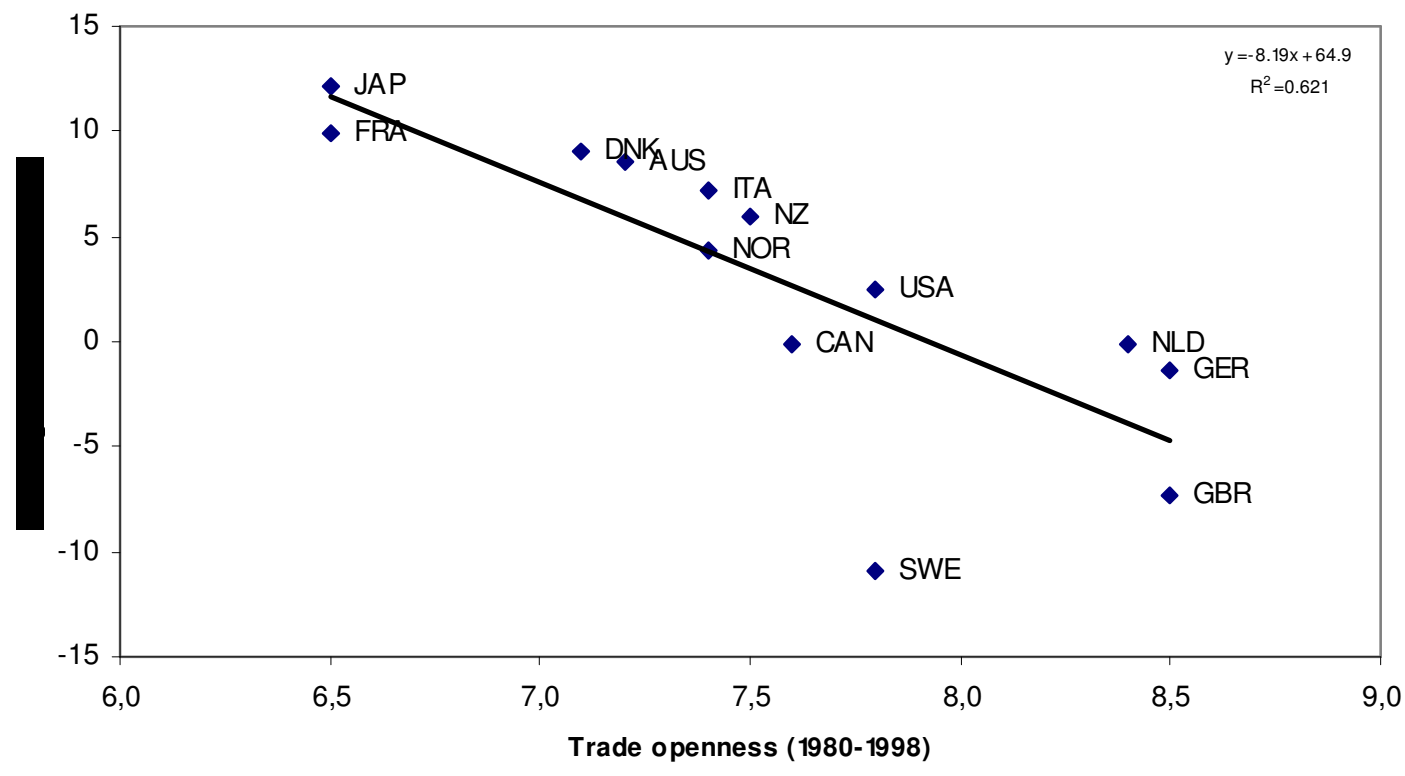




\section{Appendix}

Table A1 - Indicators of generosity 1985

\begin{tabular}{|c|c|c|c|c|c|c|}
\hline & AVGEN1 & AVGEN2 & POVGEN & INEGEN & ERGEN1 & ERGEN2 \\
\hline AUS & 3.801 & 0.359 & 48.400 & 10.9 & 62.7 & 0.000 \\
\hline CAN & 4.062 & 0.575 & 47.024 & 4.2 & 63.8 & 0.000 \\
\hline DNK & 8.254 & - & 56.260 & 3.7 & 64.5 & - \\
\hline FIN & 8.161 & 0.555 & 41.555 & 4.6 & 60.1 & 0.435 \\
\hline FRA & 10.663 & 0.792 & 68.110 & 1.1 & 61.3 & 0.545 \\
\hline DEU & 10.902 & 0.607 & 71.500 & 1.5 & 62.2 & 0.404 \\
\hline ITA & 11.000 & 0.800 & 48.518 & 2.5 & 61.6 & 0.700 \\
\hline JAP & 4.863 & - & 13.200 & 3.6 & 67.2 & - \\
\hline NLD & 8.127 & 0.637 & 59.800 & 3.0 & 61.4 & 0.722 \\
\hline $\mathrm{NZ}$ & 6.937 & 0.454 & 64.200 & 2.7 & 62.9 & 0.000 \\
\hline NOR & 5.985 & 0.357 & 53.800 & 2.3 & 66 & 0.000 \\
\hline SWE & 9.192 & 0.765 & 84.072 & 0.9 & 64.6 & 0.276 \\
\hline GBR & 7.591 & 0.385 & 60.657 & 3.2 & 64.6 & 0.255 \\
\hline USA & 6.481 & 0.517 & 33.994 & 3.9 & 64.2 & 0.000 \\
\hline
\end{tabular}

Source : OECD(2004, 2003), Förster(2003), Blondal and Scarpetta (1999) 
Table A2 - Indicators of generosity 2000

\begin{tabular}{lcccccc}
\hline & AVGEN1 & AVGEN2 & POVGEN & INEGEN & ERGEN1 & ERGEN2 \\
\cline { 2 - 6 } AUS & 5.576 & 0.351 & 50.000 & 9.7 & 60.5 & 0.000 \\
CAN & 5.167 & 0.566 & 48.878 & 3.7 & 60.8 & 0.000 \\
DNK & 8.285 & - & 61.240 & 4.3 & 60.4 & - \\
FIN & 8.575 & 0.588 & 23.270 & 6.1 & 58.6 & 0.517 \\
FRA & 12.123 & 0.750 & 78.699 & 1.1 & 58.3 & 0.456 \\
DEU & 11.904 & 0.499 & 72.000 & 1.4 & 60.4 & 0.348 \\
ITA & 13.831 & 0.800 & 58.700 & 1.4 & 59.0 & 0.420 \\
JAP & 7.961 & 0.598 & 32.400 & 3.2 & 65.5 & 0.000 \\
NLD & 7.151 & 0.614 & 60.600 & 2.9 & 58.8 & 0.693 \\
NZ & 4.900 & 0.528 & 67.100 & 4.2 & 63.4 & 0.000 \\
NOR & 6.833 & 0.320 & 63.400 & 2.3 & 62.6 & 0.000 \\
SWE & 9.852 & 0.696 & 69.893 & 1.3 & 63.0 & 0.233 \\
GBR & 8.871 & 0.481 & 50.518 & 3.4 & 61.0 & 0.194 \\
USA & 6.015 & 0.556 & 35.474 & 3.8 & 62.0 & 0.000 \\
\hline
\end{tabular}

Source : OECD(2004, 2003), Förster(2003), Burniaux, Duval and Jaumotte (2004) 
Table A3 - Correlation coefficents 1985

\begin{tabular}{|c|c|c|c|c|c|c|}
\hline & AVGEN1 & AVGEN2 & POVGEN & INEGEN & ERGEN1 & ERGEN2 \\
\hline AVGEN1 & 1.000 & & & & & \\
\hline AVGEN2 & $0.790 * * *$ & 1.000 & & & & \\
\hline POVGEN & $0.582 * *$ & 0.322 & 1.000 & & & \\
\hline INEGEN & $-0.626 * *$ & -0.496 & $-0.771 * * *$ & 1.000 & & \\
\hline ERGEN1 & -0.438 & $-0.522 *$ & -0.117 & -0.053 & 1.000 & \\
\hline ERGEN2 & $0.819 * * *$ & $0.769 * * *$ & 0.283 & -0.341 & $-0.694 * *$ & 1.000 \\
\hline
\end{tabular}


Table A4 - Correlation coefficients 2000

\begin{tabular}{lcccccc}
\hline & AVGEN1 & AVGEN2 & POVGEN & INEGEN & ERGEN1 & ERGEN2 \\
\hline AVGEN1 & 1.000 & & & & & \\
AVGEN2 & $0.538^{*}$ & 1.000 & & & & \\
POVGEN & 0.349 & 0.099 & 1.000 & & & \\
INEGEN & $-0.649^{* *}$ & $-0.503^{*}$ & $-0.623 * *$ & 1.000 & & \\
ERGEN1 & $-0.473^{*}$ & -0.330 & -0.099 & 0.083 & 1.000 & \\
ERGEN2 & $0.681^{* *}$ & $0.584^{* *}$ & 0.263 & -0.422 & $-0.777^{* * *}$ & 1.000 \\
\hline
\end{tabular}

*** significant at $1 \% ; * *$ significant at $5 \%$; * significant at $10 \%$ 
Table A5 - Change in indicators of generosity and trade openness 1995-2000

\begin{tabular}{|c|c|c|c|c|c|c|c|}
\hline & DAVGEN1 & DAVGEN2 & DPOVGEN & DINEGEN & DERGEN1 & DERGEN2 & TOI \\
\hline AUS & 1,778 & $-0,025$ & $-7,000$ & 0,805 & $-1,3$ & 0,000 & 7,20 \\
\hline CAN & $-0,234$ & $-0,006$ & 2,024 & 0,346 & $-1,5$ & 0,000 & 7,60 \\
\hline DNK & $-1,433$ & - & $-4,030$ & 0,753 & $-2,3$ & - & 7,10 \\
\hline FIN & $-1,164$ & $-0,006$ & $-7,561$ & 2,243 & $-0,4$ & $-0,012$ & 6,70 \\
\hline FRA & 0,017 & $-0,033$ & 0,720 & 0,134 & $-0,9$ & $-0,042$ & 6,50 \\
\hline DEU & 0,730 & $-0,026$ & 1,900 & $-0,033$ & $-0,1$ & $-0,021$ & 8,50 \\
\hline ITA & 0,508 & 0,000 & 3,025 & 0,043 & $-1,6$ & $-0,280$ & 7,40 \\
\hline JAP & 2,045 & $-0,038$ & 7,000 & $-0,410$ & $-1,0$ & 0,000 & 6,50 \\
\hline NLD & $-0,851$ & 0,025 & 0,900 & $-0,201$ & 0,0 & 0,006 & 8,40 \\
\hline NZ & $-0,680$ & 0,089 & $-3,100$ & 1,070 & 1,4 & 0,000 & 7,50 \\
\hline NOR & $-0,674$ & $-0,002$ & 5,200 & 0,048 & $-1,2$ & 0,000 & 7,40 \\
\hline SWE & $-0,775$ & $-0,040$ & $-3,312$ & 0,166 & $-0,3$ & $-0,018$ & 7,80 \\
\hline GBR & 0,131 & 0,024 & $-2,870$ & $-0,133$ & $-1,7$ & $-0,038$ & 8,50 \\
\hline USA & $-0,333$ & 0,011 & $-0,987$ & 0,092 & $-1,6$ & 0,000 & 7,80 \\
\hline
\end{tabular}


Table A6 - Correlation coefficients of changes 1985-1995

\begin{tabular}{lcccccc}
\hline & DAVGEN1 & DAVGEN2 & DPOVGEN & DINEGEN & DERGEN1 & DERGEN2 \\
\cline { 2 - 6 } TOI & -0.433 & -0.246 & $-0.678^{* * *}$ & 0.397 & -0.212 & -0.384 \\
\hline
\end{tabular}

*** significant at $1 \% ; * *$ significant at $5 \% ; *$ significant at $10 \%$ 
Table A7 - Correlation coefficients of changes 1995-2000

\begin{tabular}{ccccccc}
\hline & DAVGEN1 & DAVGEN2 & DPOVGEN & DINEGEN & DERGEN1 & DERGEN2 \\
\cline { 2 - 6 } TOI & -0.031 & 0.390 & 0.050 & -0.335 & 0.108 & 0.027 \\
\hline
\end{tabular}

*** significant at $1 \% ; * *$ significant at $5 \%$; * significant at $10 \%$ 
Table A8 Correlation coefficients of changes 1985-1995 (without Finland)

\begin{tabular}{lcccccc}
\hline & DAVGEN1 & DAVGEN2 & DPOVGEN & DINEGEN & DERGEN1 & DERGEN2 \\
\cline { 2 - 6 } TOI & -0.376 & -0.160 & $-0.920^{* * *}$ & 0.387 & -0.177 & -0.292 \\
\hline
\end{tabular}

*** significant at $1 \%$;** significant at $5 \%$; significant at $10 \%$ 
Table A9 Correlation coefficients of changes 1995-2000 (without Finland)

\begin{tabular}{lcccccc}
\hline & DAVGEN1 & DAVGEN2 & DPOVGEN & DINEGEN & DERGEN1 & DERGEN2 \\
\cline { 2 - 6 } TOI & -0.168 & 0.373 & -0.077 & -0.273 & 0.149 & 0.020 \\
\hline *** significant at $1 \%$; ** significant at 5\% ; * significant at 10\% & & &
\end{tabular}




\section{Notes}

This paper is an extension of Pestieau (2006).

ii Casamatta et al. (2002).

Conde-Ruiz and Profeta (2003).

iv Cremer et al. (2004).

$\checkmark \quad$ Cremer and Pestieau (2003).

vi Pestieau (2005).

Spearman's measure of, contrary to Pearson, does not make any assumption on the distribution of variables and is robust to outliers.

viii This indicator was published by the CATO Institute in its 2001 report; it is richer than the usual ratio of exports plus imports to GDP. We use it for the 1980-1998 period.

${ }^{\text {ix }}$ We tried some other specifications like pooling the data from 1995 and 2000 or adding others explicative variables (dependancy ratio and social spending) and it did not change the sign and the significance of the results. We prefer keeping this specification because of graphical representation. 